\section{BRAZIULIAN JOURNAL \\ OF MIEDICAL AND BIOLOGICAL RESFARCH}

www.bjournal.com.br
ISSN 0100-879X

Volume 42 (8) 692-775 August 2009

CLINICAL INVESTIGATION

Braz J Med Biol Res, August 2009, Volume 42(8) 700-706

Spot urine porphyrins/creatinine ratio profile of healthyBrazilian individuals adjusted for personal habits

A.N.L. Alves, N.M. Sumita, M.N. Burattini and H.V. Della Rosa

The Brazilian Journal of Medical and Biological Research is partially financed by
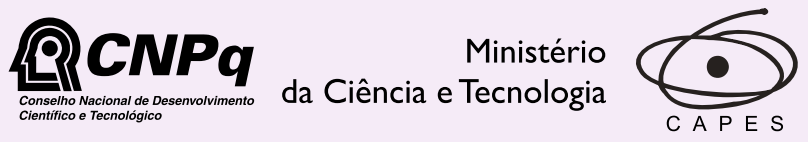

Ministério da Educação

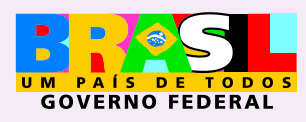

Institutional Sponsors 


\title{
Spot urine porphyrins/creatinine ratio profile of healthy Brazilian individuals adjusted for personal habits
}

\author{
A.N.L. Alves ${ }^{1,2}$, N.M. Sumita1 ${ }^{1}$, M.N. Burattini ${ }^{1}$ and H.V. Della Rosa ${ }^{2}$ \\ 1'Divisão de Laboratório Central e Laboratório de Investigação Médica, LIM-03, Hospital das Clínicas, \\ Faculdade de Medicina, ${ }^{2}$ Faculdade de Ciências Farmacêuticas, Universidade de São Paulo, São Paulo, \\ SP, Brasil
}

Correspondence to: M.N. Burattini, Av. Dr. Enéas de Carvalho Aguiar, 155, Prédio dos Ambulatórios, Divisão de Laboratório Central, 2o andar, Bloco 8, 05403-000 São Paulo, SP, Brasil

Fax: +55-11-3069-6109. E-mail: mnburatt@usp.br

\begin{abstract}
Changes in urinary porphyrin excretion may be the result of hereditary causes and/or from environmental or occupational exposure. The objective of this study was to measure the amount of some porphyrins in spot urine samples obtained from volunteers randomly selected from a healthy adult population of São Paulo with a sensitive HPLC method and to estimate normal ranges for a non-exposed population. Spot urine samples were collected from 126 subjects (both genders, 18 to 65 years old) not occupationally exposed to porphyrinogenic agents. Porphyrin fractions were separated on RP-18 HPLC column eluted with a methanol/ammonium acetate buffer gradient, $\mathrm{pH} 4.0$, and measured fluorometrically (excitation $405 \mathrm{~nm} / \mathrm{emission} 620 \mathrm{~nm}$ ). The amount of porphyrins was corrected for urinary creatinine excretion. Only 8-carboxyl (uro) and 4-carboxyl (copro) porphyrins were quantified as $\mu \mathrm{g} / \mathrm{g}$ creatinine. Data regarding age, gender, occupational activities, smoking and drinking habits were analyzed by Mann-Whitney and Kruskal-Wallis tests. Uroporphyrin results did not differ significantly between the subgroups studied. Copro and uro + copro porphyrins were significantly different for smokers $(P=0.008)$ and occupational activities $(P=$ 0.004). With respect to alcohol consumption, only men drinking $>20 \mathrm{~g} /$ week showed significant differences in the levels of copro $(P=0.022)$ and uro + copro porphyrins $(P=0.012)$. The 2.5-97.5th percentile limit values, excluding those for subjects with an alcohol drinking habit $>20 \mathrm{~g} /$ week, were $0-20.8,11.7-93.1$, and 15.9-102.9 $\mu \mathrm{g} / \mathrm{g}$ creatinine for uro, copro and uro + copro porphyrins, respectively. These percentile limit values can be proposed as a first attempt to provide urinary porphyrin reference values for our population, serving for an early diagnosis of porphyrinopathies or as biomarkers of exposure to porphyrinogenic agents.
\end{abstract}

Key words: Spot urine; Urinary porphyrins; Healthy population; Reference values

Research supported by LIM 03-HCFMUSP, Fundação Faculdade de Medicina and Faculdade de Ciências Farmacêuticas, Universidade de São Paulo.

Received October 3, 2008. Accepted March 27, 2009

\section{Introduction}

Porphyrins are intermediates of the heme biosynthesis pathway, ranging from eight to four carboxyl groups known as uroporphyrin (8-carboxyl), hepta, hexa, penta, and coproporphyrin (4-carboxyl), respectively (1). The predominant porphyrin in urine of healthy individuals is coproporphyrin (copro), followed by uroporphyrin (uro) at minor concentrations (2). Porphyrias are inherited or acquired metabolic disorders whose clinical cutaneous, neurologic or visceral manifestations are related to characteristic patterns of overproduction of specific heme precursors. There are eight known enzymes involved in heme biosynthesis and enzymatic defects in any subsequent step lead to an excessive excretion of porphyrins and/or their precursors (3). When clinically active, and in some cases even when latent or in clinical remission, porphyrias induce high levels of heme precursors in blood, urine, and/or stool (1). 
Some of the inherited porphyrias occur predominantly as toxicogenetic conditions in which the genetic trait is latent until clinical manifestations of porphyria are triggered idiosyncratically by external factors $(1,4)$. These conditions have been observed after exposure to chemicals such as polychlorinated biphenyls (5), hexachlorobenzene (6), pentachlorophenol $(1,7)$, and dioxins (8) and heavy metals such as arsenic $(9,10), \mathrm{Hg}(3)$, and $\mathrm{Pb}(11)$. They can also occur in individuals infected by some viruses such as HBV (12), HCV (12-14), and $\operatorname{HIV}(15,16)$ or exposed to illicit or therapeutic drugs like alcohol (17), to prolonged therapeutic use of estrogens (18) and to iron overload (13), and as adverse effects of drugs like anticonvulsants (19) and anesthetics (20). In addition, these factors can cause porphyrias in individuals with no documented genetic predisposition as an acquired toxin-induced condition $(1,4)$.

Porphyria cutanea tarda is the most common of human porphyrias and results from partial deficiency of the enzyme uroporphyrinogen decarboxylase producing the accumulation of uro and heptacarboxylporphyrins and a predominance of cutaneous symptomatology. It can result from inherited or acquired conditions or a mixture of both (21).

Disturbances of heme synthesis are associated with alterations of subcellular structure and function that can be related to the clinical signs and symptoms of porphyrias and produce characteristic changes in heme-precursor excretion. These measurable changes offer potential biological markers for detecting the harmful effects of specific chemical exposure while their biological effects are still preclinical and potentially reversible $(1,5)$. However, most clinicians, including specialists in occupational and environmental medicine, are relatively uninformed about these phenomena (1).

Urinary porphyrin excretion is the key tool for the diagnosis of disorders of the heme biosynthesis pathway and, although several spectrofluorometric techniques are available they are not sensitive enough to detect the five fractions (22). Therefore, the method of choice to determine urinary porphyrin fractions is gradient RP-HPLC using $\mathrm{C} 18$ columns with fluorescence detection (22). In addition to methodological limitations, the interpretation of any laboratory test for porphyrins can be affected by personal factors such as gender, age, occupational activity, smoking and drinking habits (1).

The purpose of the present study was to determine the normal range values for uro, copro, and uro + copro porphyrin/creatinine ratio in urine samples from healthy volunteers to provide a tool for the early diagnosis of porphyrinopathies and for use as biomarkers of exposure to porphyrinogenic agents.

\section{Material and Methods}

\section{Study population and data collection}

A total of 141 volunteers of both genders aged 18 to 65 years old, living in São Paulo city, Brazil, were screened from 2003 to 2005. Individuals in the sample were randomly selected from 12,500 workers of a tertiary university hospital. The institutional Research Ethics Committee reviewed and approved the research protocol and all volunteers gave written informed consent to participate in the study.

Exclusion criteria were: reported hereditary hemoglobinopathies, liver or kidney diseases (1); altered parameters in urinalysis (qualitative and quantitative analysis of urinary elements) (23); or urinary creatinine values below $0.3 \mathrm{~g} / \mathrm{L}$, according to WHO recommendations for the adjustment of biological urinary indicators (24).

Fifteen volunteers were excluded from the study for the following reasons: one for hereditary hemoglobinopathy, which is a known cause of secondary coproporphyrinuria (1); two for presenting urinary creatinine below $0.3 \mathrm{~g} / \mathrm{L}$, considered too diluted for proper analysis (24), and the remaining 12 volunteers for abnormal urinalysis results according to NCCLS standards (23).

Urinary samples were collected according to standard techniques in the early morning, into polypropylene flasks protected from light. Samples were then separated into two aliquots, one of which was immediately alkalinized with sodium bicarbonate and stored under refrigeration (2$8^{\circ} \mathrm{C}$ ) until porphyrin analysis. The adjustment of concentration-dilution of the spot urine sample was carried out by determining urinary creatinine in the remaining aliquot by the method of Jaffe, as described by Heinegard et al. (25).

All subjects were also requested to fill out a standardized questionnaire to obtain information about age, place of residence, type of work (technical or administrative), food intake, personal habits (smoking, alcohol intake and hobby activities) and exposure to pharmaceutical drugs in order to provide baseline data for analysis of the risk of the presence of porphyrin in urine.

\section{Urinary porphyrin analysis}

Urinary porphyrins and their homologues were analyzed by a high-performance liquid chromatography (HPLC) protocol adapted from the method described by Sunyer et al. (6), and published by Alves et al. (26) as described below. Chemicals used for buffered phase preparation were of analytical grade. Ammonium acetate, acetic acid and methanol were purchased from Merck AG (Germany). 
Water was purified using a Milli-Q system from Millipore (USA). Porphyrin standards and controls were purchased from Immundiagnostik (Germany).

Briefly, a 2-mL urine sample was acidified with $70 \mu \mathrm{L}$ $\mathrm{HCl}$ and a $100-\mu \mathrm{L}$ aliquot was injected into a modular HPLC apparatus (Shimadzu Co., Japan) after 10-min centrifugation at $1500 \mathrm{~g}$ and filtration through a $0.45-\mu \mathrm{m}$ Millipore filter. The HPLC system consisted of two high-pressure pumps (LC-10AD), gradient controller (SCL-10A), auto-sampler (SIL-10A), and fluorescence detector (RF535, excitation: $400 \mathrm{~nm}$ and emission: $620 \mathrm{~nm}$ ). The sensitivity of the method was $8.0 \mu \mathrm{g} / \mathrm{L}$ for each porphyrin homologue.

All porphyrins were separated on a Lichrosphere 100RP column (125 x $4 \mathrm{~mm}$ ) guarded by a Lichrosphere 100$\mathrm{RP}(4 \times 4 \mathrm{~mm})$ precolumn, both with a particle size of $5 \mu \mathrm{m}$ and purchased from Merck AG. Flow rate was $1 \mathrm{~mL} / \mathrm{min}$. Separation conditions for optimized gradient elution of porphyrins were as follows: mobile phase A consisting of $1.0 \mathrm{M}$ ammonium acetate, $\mathrm{pH} 4.0$, and mobile phase $\mathrm{B}$ consisting of $100 \%$ methanol. The gradient program for phase B was as follows: isocratic 10\% B during the first minute, linear increase from 10 to $95 \%$ in the subsequent 12 min and linear decrease from 95 to $10 \%$ in the last 3 $\min$.

\section{Statistical analysis}

Associations of urinary concentrations of uro, copro and uro + copro porphyrins with the independent variables age, gender, occupational activity, and smoking and drinking habits were analyzed statistically by Mann-Whitney and Kruskal-Wallis tests, when applicable $(27,28)$. Bonferroni multiple comparison was further applied to the variables with a significant difference by the Kruskal-Wallis test. The level of significance was set at 0.05 and analyses were performed with the Statistical Package for the Social Sciences (SPSS), version 10.0 .

\section{Results}

After exclusion criteria were applied with 15 volunteers being excluded, the remaining 126 subjects constituted the study sample ( 67 women and 59 men). Table 1 describes their demographic characteristics and alcohol intake and smoking habits.
Overall mean \pm SD values for uro, copro, and uro + copro porphyrins reported as $\mu \mathrm{g} / \mathrm{g}$ urinary creatinine were $5.3 \pm 6.0,42.8 \pm 26.4$, and $48.1 \pm 27.7 \mu \mathrm{g} / \mathrm{g}$, respectively. Only uro and copro porphyrin fractions could be quantified, with uro + copro porphyrins reported by their sum. Table 2 shows the median, $25-75 \%$ range and $P$ values for uro, copro, and uro + copro porphyrins stratified by age, gender, occupational activity, and smoking and drinking habits.

Figure 1 shows the total distribution of uro, copro, and uro + copro porphyrins values stratified for the variables with significant differences in Table 2 (professional activity, smoking and drinking habits). Hospital laboratory employees involved in technical activities, when compared to those with administrative functions, presented higher concentrations of urinary copro (median $45.5 \mathrm{vs} 30.5 \mu \mathrm{g} / \mathrm{g}$ creatinine, $\mathrm{P}=0.004$ ) and uro + copro porphyrins (median 47.3 vs $34.9 \mu \mathrm{g} / \mathrm{g}$ creatinine, $\mathrm{P}=0.007$ ). Smokers presented lower values than non-smokers for copro (median 22.5 and $37.2 \mu \mathrm{g} / \mathrm{g}$ creatinine, $\mathrm{P}=0.008$ ) and uro + copro porphyrins (median 27.2 and $43.5 \mu \mathrm{g} / \mathrm{g}$ creatinine, $\mathrm{P}=$ 0.019). With respect to alcohol consumption, only men showed statistically significant differences (see Table 3 and Figure 1$)$ in the levels of copro $(P=0.022)$ and uro + copro porphyrins $(P=0.012)$. Bonferroni analysis of these differences showed that individuals with an alcohol consumption $>20 \mathrm{~g} /$ week had higher copro porphyrin levels compared to those with an alcohol consumption $\leq 20 \mathrm{~g} /$ week $(P=0.047)$ and to those with no alcohol consumption

Table 1. Demographic data of the subjects studied.

\begin{tabular}{lccc}
\hline & Males $(\mathrm{N}=59)$ & Females $(\mathrm{N}=67)$ & Total $(\mathrm{N}=126)$ \\
\hline Age (years) & $39.5 \pm 6.0$ & $40.9 \pm 6.2$ & $40.2 \pm 6.1$ \\
$\quad$ Range & $19-59$ & $18-65$ & $18-65$ \\
$18-40$ years old & $30.1 \pm 6.2$ & $33.5 \pm 5.5$ & $31.8 \pm 5.9$ \\
& $(\mathrm{~N}=41)$ & $(\mathrm{N}=31)$ & $(\mathrm{N}=72)$ \\
$>40$ years old & $48.9 \pm 5.8$ & $48.2 \pm 6.9$ & $48.6 \pm 6.4$ \\
& $(\mathrm{~N}=18)$ & $(\mathrm{N}=36)$ & $(\mathrm{N}=54)$ \\
Occupational activity $(\mathrm{N})$ & & & \\
$\quad$ Technicians & 16 & 43 & 59 \\
Management & 43 & 24 & 109 \\
Smoking habit $(\mathrm{N})$ & & & 17 \\
$\quad$ Non-smokers & 53 & 56 & \\
Smokers & 6 & 11 & 42 \\
Drinking habit $(\mathrm{N})$ & & & 74 \\
None & 18 & 24 & 10 \\
$\leq 20$ g/week & 32 & 42 & \\
$>20$ g/week & 9 & 1 & \\
\end{tabular}

Age is reported as means $\pm \mathrm{SD}$. Occupational activity, smoking and drinking habit are reported as number of subjects $(\mathrm{N})$. 
Table 2. Median and 25th-75th percentiles for uro, copro, and uro + copro porphyrins ( $\mu \mathrm{g} / \mathrm{g}$ creatinine) and $\mathrm{P}$ value for subjects divided into subgroups.

\begin{tabular}{|c|c|c|c|c|c|c|}
\hline \multirow[t]{2}{*}{ Groups } & \multicolumn{2}{|c|}{ Uro } & \multicolumn{2}{|c|}{ Copro } & \multicolumn{2}{|c|}{ Uro + copro } \\
\hline & Median & $25-75$ & Median & $25-75$ & Median & $25-75$ \\
\hline \multicolumn{7}{|l|}{ Age } \\
\hline$\leq 40$ years old $(\mathrm{N}=72)$ & 5.6 & $0-7.9$ & 33.6 & $20.9-56.8$ & 40.0 & $25.1-60.1$ \\
\hline$>40$ years old $(\mathrm{N}=54)$ & 5.0 & $0-9.8$ & 38.4 & $24.1-62.4$ & 42.6 & $28.7-70.9$ \\
\hline \multicolumn{7}{|l|}{ Gender } \\
\hline Females $(\mathrm{N}=67)$ & 4.6 & $0-9.4$ & 34.8 & 23.3-56.4 & 42.9 & $28.5-65.0$ \\
\hline Males $(N=59)$ & 4.7 & $0-8.0$ & 33.8 & 19.5-59.6 & 40.8 & $23.0-64.0$ \\
\hline \multicolumn{7}{|l|}{ Occupational activity } \\
\hline Management $(\mathrm{N}=67)$ & 4.6 & $0-8.0$ & $30.5^{*}$ & $19.0-52.3$ & $34.9^{*}$ & $23.5-53.5$ \\
\hline Technicians $(\mathrm{N}=59)$ & 5.7 & $0-9.3$ & 45.5 & $28.7-69.4$ & 47.3 & $31.4-78.0$ \\
\hline \multicolumn{7}{|l|}{ Smoking habit } \\
\hline No $(N=109)$ & 4.6 & $0-8.8$ & $37.2^{*}$ & 23.4-59.6 & $43.5^{\star}$ & $28.3-64.3$ \\
\hline Yes $(N=17)$ & 7.2 & $0-11.1$ & 22.5 & $13.0-36.4$ & 27.2 & $20.1-40.6$ \\
\hline \multicolumn{7}{|c|}{ Drinking habit/alcohol consumed in a week (g) } \\
\hline $0(N=42)$ & 5.7 & $0-9.5$ & 33.6 & $23.4-54.3$ & 39.0 & $28.5-57.0$ \\
\hline$\leq 20.0 \mathrm{~g}$ per week $(\mathrm{N}=74)$ & 4.5 & $0-8.3$ & 31.2 & $21.2-56.5$ & 40.5 & $26.2-60.0$ \\
\hline$>20.0$ g per week $(N=10)$ & 4.3 & $0-8.6$ & 70.6 & $30.3-94.1$ & 75.8 & $37.1-106.2$ \\
\hline Total $(N=126)$ & 4.7 & $0-8.9$ & 34.0 & $22.4-59.8$ & 48.1 & $27.4-65.4$ \\
\hline
\end{tabular}

Comparisons were made by the Mann-Whitney test except when otherwise indicated and asterisks denote $\mathrm{P}<0.05$. Individuals were classified as smokers if smoking $>5$ cigarettes/day. The Kruskal-Wallis test was used to analyze data for alcohol intake.
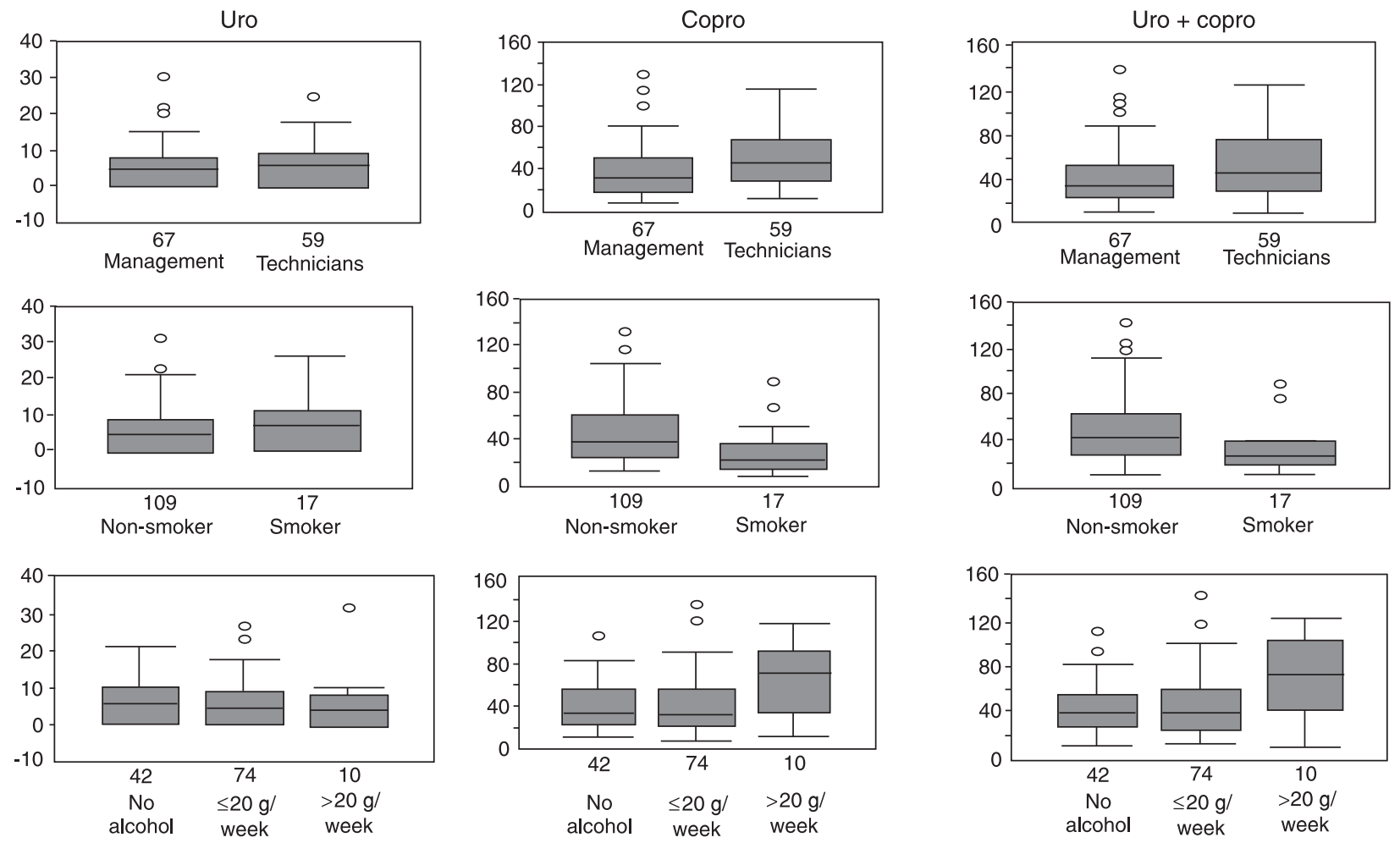

Figure 1. Box-and-whisker plot for urinary levels of uro, copro, and uro + copro porphyrins according to occupational activity and smoking and drinking habits (126 individuals, São Paulo, SP, Brazil). Points are outliers, the box indicates the interquartile range, the whiskers indicate the range, and the horizontal line within the box is the median. 
Table 3. Median and interquartile interval (25-75\%) for urinary copro and uro + copro porphyrins ( $\mu \mathrm{g} / \mathrm{g}$ creatinine) in male subjects classified into subgroups according to alcohol consumption per week.

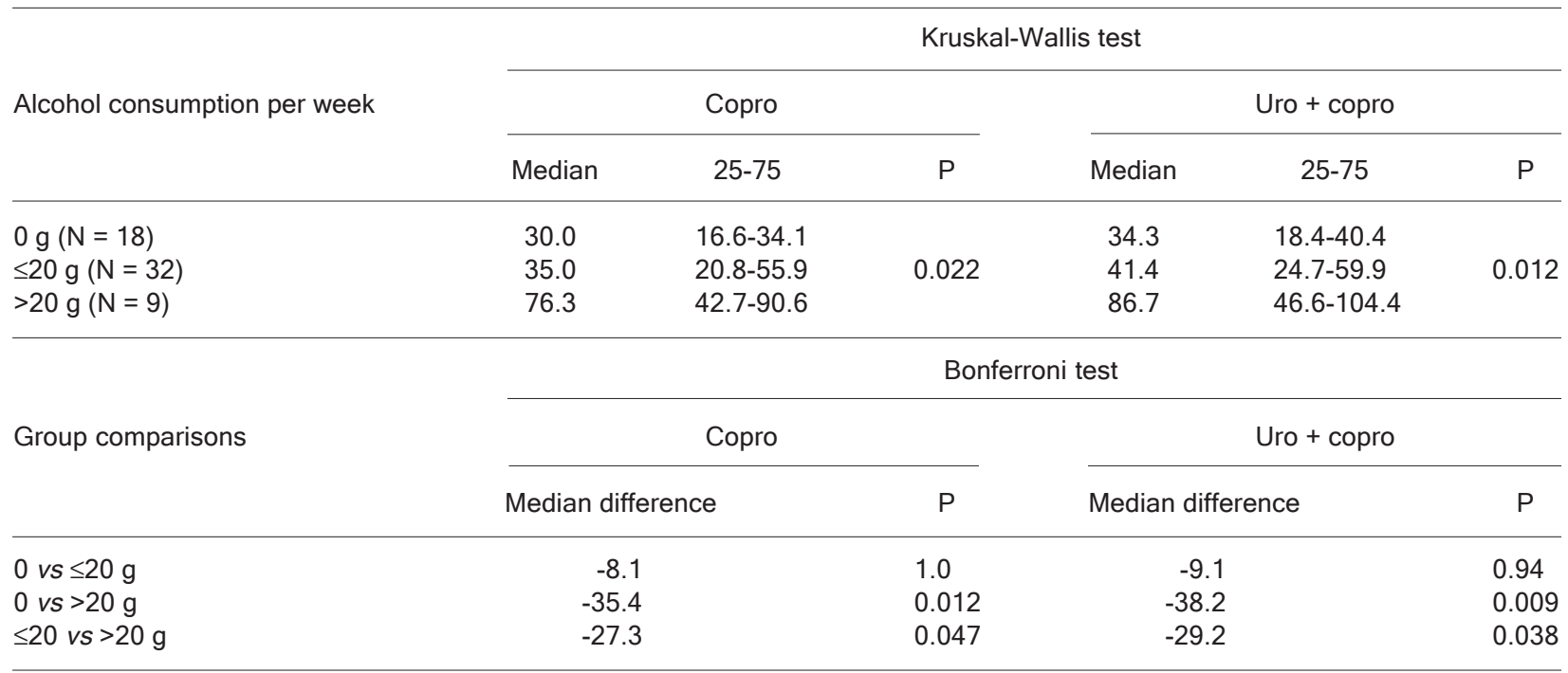

at all $(P=0.012)$. The latter two groups did not differ significantly from one another (see Table 3). The same behavior was observed for uro + copro porphyrins, with men with an alcohol consumption $>20 \mathrm{~g} /$ week having higher levels than those with an alcohol consumption $\leq 20$ $\mathrm{g} /$ week $(P=0.038)$ and those with no alcohol consumption at all $(P=0.009)$. Again, the latter two groups showed no statistical difference from one another (see Table 3).

Due to the non-normal distribution of the uro and copro fractions, the $95 \%$ confidence intervals $(95 \% \mathrm{Cl})$ were determined by cutting off the 2.5 and $97.5 \%$ percentiles, as recommended by Apostoli (29). The 2.5-97.5th percentiles obtained, excluding subjects who reported more than $20 \mathrm{~g} /$ week of alcohol consumption, were: $0-20.8 \mu \mathrm{g} / \mathrm{g}$ creatinine for uro, 11.7-93.1 creatinine for copro, and 15.9-102.9 $\mu \mathrm{g} /$ $\mathrm{g}$ creatinine for uro + copro porphyrins.

\section{Discussion}

The aim of the present investigation was to determine the characteristic profile of urinary porphyrins in spot urine samples from a normal population in order to establish reference values and, therefore, to provide tools for an early diagnosis of porphyrinopathies and to allow the use of these values as biomarkers of exposure to porphyrinogenic agents. Urinary excretion of porphyrins in spot urinary samples has been shown to reflect total daily excretion, avoiding the problems of collecting 24-h specimens (30). Since porphobilinogen can polymerize to porphyrin or be non-enzymatically converted to porphyrins, it is very important to protect urine samples from light and to store them between 2 and $8^{\circ} \mathrm{C}(2)$.

Our sample represented a population of highly heterogeneous ethnic origin, as is usual in Brazil. The State of São Paulo receives migrants from different parts of the country, and people of European, Mediterranean, African, and Asian origin are common. Thus, ours was a multiethnic sample living in a city with high-density traffic and in which air pollution is of particular concern, with carbon monoxide, sulfur, nitrogen dioxides, and particulate material measured daily around the city by the São Paulo State Sanitary Agency (CETESB, 2005), and being frequently above the recommended levels (31). Although, to the best of our knowledge, there are no published reports relating air pollutants to urinary porphyrin excretion, we believe that a description of the ethnic and environmental background of our sample would be important for future comparisons with other published results.

The size of our sample (126) met the requirements of the International Federation of Clinical Chemistry (IFCC) (32) and Clinical and Laboratory Standards Institute (CLSI) (33) that recommend at least 120 individuals to estimate the reference range and $95 \% \mathrm{Cl}$ for a new laboratory value to be applied to a healthy population.

Of the five porphyrin fractions known, we were able to quantitatively measure only uro and copro porphyrins in spot urinary samples. The fraction with 7 carboxyl groups was detected in $21 / 126$ individuals (16.5\%) of our sample, 
but its values were below the quantification limit as were fractions with 6 and 5 carboxyl groups. Similar findings have been reported by Sunyer et al. (6), who found the hepta fraction in only $7 \%$ of their subjects and also did not detect the other fractions.

Our findings for uro $(5.3 \pm 6.0 \mu \mathrm{g} / \mathrm{g}$ creatinine $)$, copro $(41.0 \pm 25.2 \mu \mathrm{g} / \mathrm{g}$ creatinine) and uro + copro porphyrins $(46.2 \pm 26.3 \mu \mathrm{g} / \mathrm{g}$ creatinine) agree with the data reported by Buratti et al. (34) for total porphyrins. Apostoli et al. (10) detected higher values for uro, copro, and uro + copro porphyrins, namely $9.4 \pm 11.4,70.5 \pm 36.7$, and $89.8 \pm$ 44.8 , respectively, using analytical methodology similar to that which we used. The differences found could, therefore, be attributed to the different populations studied.

We found no gender differences in urinary porphyrin profiles, also in agreement with other published reports (35).

We found that smokers had lower copro and uro + copro porphyrin levels (Table 2). However, since only $13.5 \%$ of our sample smokes, and there are no published data relating changes in urinary porphyrin excretion to smoking habit, we believe that further studies are needed in order to properly address these findings. Nevertheless, it has been reported that benzopyrene derivatives presented in cigarette smoke can interfere with CYP 450, inducing higher activation of that enzymatic system (36).

Santos et al. (37) found a significant association between alcohol intake and porphyrinuria in non-porphyric adults. Alcohol consumption may trigger a hidden hereditary (or non-hereditary) predisposition to a condition of altered porphyrin metabolism or of overt hepatic porphyria (17).

We excluded individuals reporting an alcohol consumption $>20 \mathrm{~g} /$ week from the calculation of the $95 \% \mathrm{Cl}$ presented in this study in order to obtain a proper definition of what could be thought to be the upper reference value for a normal population.

To define new normal laboratory profiles for healthy individuals, establishing reference values related to gender, age and personal habits, plays an important role in population medicine. Furthermore, these values are required for assessing the health status of patients (29) and are a basic tool for biomonitoring programs in occupational and environmental medicine (34).

Laboratory test results can, in general, be compromised by a variety of factors, including specimen integrity (reflecting conditions of specimen collection, processing, transport and storage), analytical quality control practices and limitations of the analytical methods (37). Sample protection from light is very important for porphyrin analysis since the fluorescence of porphyrins can decrease if exposed to light (4).

Although urinary porphyrins are a highly sensitive and specific biomarker for altered heme biosynthesis, they lack specificity for identifying the enzyme, co-factor, etc. responsible for this metabolic alteration. In such cases, some enzyme activities of the heme biosynthetic pathway must be quantified and/or the possible porphyrinogenic agent implicated should be investigated.

The aim of this study was to establish reference values for a healthy population. However, the sample used, 126 subjects, was not large enough to allow multivariate analysis of risk factors associated with alterations in urinary porphyrin excretion. Thus, the study of more subjects will provide more information on other possible risk factors for an altered spot urinary porphyrin profile.

Finally, although the present results were derived only from a sample of the São Paulo city population, we believe they can be used to provide tentative reference levels for other regional studies in Brazil or other countries, and to serve as a proxy to detect slight, but sometimes irreversible, changes in heme biosynthesis.

\section{References}

1. Daniell WE, Stockbridge HL, Labbe RF, Woods JS, Anderson $\mathrm{KE}$, Bissell DM, et al. Environmental chemical exposures and disturbances of heme synthesis. Environ Health Perspect 1997; 105 (Suppl 1): 37-53.

2. Nordmann $\mathrm{Y}$, Puy H. Human hereditary hepatic porphyrias. Clin Chim Acta 2002; 325: 17-37.

3. Pingree SD, Simmonds PL, Rummel KT, Woods JS. Quantitative evaluation of urinary porphyrins as a measure of kidney mercury content and mercury body burden during prolonged methylmercury exposure in rats. Toxicol Sci 2001; 61: 234-240.

4. Hindmarsh JT. The porphyrias, appropriate test selection. Clin Chim Acta 2003; 333: 203-207.

5. Cho JH, Jeong SH, Yun HI. Changes of urinary and blood porphyrin profiles by exposure to PCBs, lead or diazinon in rats. Vet Hum Toxicol 2003; 45: 193-198.

6. Sunyer J, Herrero C, Ozalla D, Sala M, Ribas-Fito N, Grimalt $\mathrm{J}$, et al. Serum organochlorines and urinary porphyrin pattern in a population highly exposed to hexachlorobenzene. Environ Health 2002; 1: 1.

7. Hryhorczuk DO, Wallace WH, Persky V, Furner S, Webster $\mathrm{JR} J \mathrm{~J}$, Oleske $\mathrm{D}$, et al. A morbidity study of former pen- 
tachlorophenol-production workers. Environ Health Perspect 1998; 106: 401-408.

8. Elder $\mathrm{GH}$, Urquhart AJ. Biochemical indices of liver toxicity: porphyrin metabolism. In: Foá V, Emmet EA, Maroni M, Colombi A (Editors), Occupational and environmental chemical hazards: cellular and biochemical indices for monitoring toxicity. Chichester: Ellis Horwood; 1987. p 232-290.

9. Wu H, Manonmanii K, Lam PK, Huang SH, Wang JP, Ng JC. Urinary arsenic speciation and porphyrins in C57BI/6J mice chronically exposed to low doses of sodium arsenate. Toxicol Lett 2004; 154: 149-157.

10. Apostoli P, Sarnico M, Bavazzano P, Bartoli D. Arsenic and porphyrins. Am J Ind Med 2002; 42: 180-187.

11. Costa CA, Trivelato GC, Pinto AM, Bechara EJ. Correlation between plasma 5-aminolevulinic acid concentrations and indicators of oxidative stress in lead-exposed workers. Clin Chem 1997; 43: 1196-1202.

12. Navas $S$, Bosch O, Castillo I, Marriott E, Carreno V. Porphyria cutanea tarda and hepatitis $C$ virus and $B$ virus infection: a retrospective study. Hepatology 1995; 21: 279-284.

13. Cribier B, Chiaverini C, Dali-Youcef N, Schmitt M, Grima M, Hirth $\mathrm{C}$, et al. Porphyria cutanea tarda, hepatitis $\mathrm{C}$, uroporphyrinogen decarboxylase and mutations of HFE gene. A case-control study. Dermatology 2009; 218: 15-21.

14. Sterling RK, Bralow S. Extrahepatic manifestations of hepatitis C virus. Curr Gastroenterol Rep 2006; 8: 53-59.

15. Almehmi A, Deliri H, Szego GG, Teague AC, Pfister AK, Martin SA. Porphyria cutanea tarda in a patient with HIVinfection. WV Med J 2005; 101: 19-21.

16. Melito VA, Parera VE, Rossetti MV, Batlle A. Porphyria cutanea tarda manifestation in patients infected with human immunodeficiency virus. Acta Bioquim Clin Latinoam 2006; 40: 29-34.

17. Doss MO, Kuhnel A, Gross U. Alcohol and porphyrin metabolism. Alcohol Alcohol 2000; 35: 109-125.

18. Mor Z, Caspi E. Cutaneous complications of hormonal replacement therapy. Clin Dermatol 1997; 15: 147-154.

19. Tutor-Crespo MJ, Hermida J, Tutor JC. Effect of antiepileptic drugs on the urinary excretion of porphyrins in nonporphyric subjects. J Pharmacol Sci 2005; 99: 323-328.

20. Verdon CP, Pollock TA, Bralley JA. Testing for toxic metals and chemical induced porphyrinuria. http://www.metametrix.com/ Publications/Toxic\%20Metals. Accessed March 19, 2009.

21. Poblete-Gutiérrez $P$, Wiederholt T, Merk HF, Frank J. The porphyrias: clinical presentation, diagnosis and treatment. Eur J Dermatol 2006; 16: 230-240.

22. Johnson PM, Perkins SL, Kennedy SW. A high-speed liquid-chromatographic method for measuring urinary porphyrins. Clin Chem 1988; 34: 103-105.

23. CLSI (Clinical Laboratory Standards Institute). Urinalysis; approved guideline. 3rd edn. Wayne: Vol. 29, No. 4, Document GP16-A3; 2009.

24. WHO (World Health Organization). Biological monitoring of chemical exposure in the workplace. Vol. 1. Geneva: World Health Organization; 1996.

25. Heinegard D, Tiderstrom G. Determination of serum creatinine by a direct colorimetric method. Clin Chim Acta 1973; 43: 305-310.

26. Alves ANL, Burattini MN, Sumita NM, Rosa HVD. Validation of a high performance liquid chromatography method for quantification of urinary porphyrins. Braz J Pharmac Sci 2007; 43: 581-588.

27. Conover WJ. Practical nonparametric statistics. 2nd edn. New York: John Wiley and Sons; 1980

28. Bussab WO, Morettin PA. Estatística básica. 4th edn. São Paulo: Atual; 1987.

29. Apostoli P. Application of reference values in occupational health. Int Arch Occup Environ Health 1999; 72: 191-194.

30. Woods JS, Martin MD, Leroux BG. Validity of spot urine samples as a surrogate measure of 24-hour porphyrin excretion rates. Evaluation of diurnal variations in porphyrin, mercury, and creatinine concentrations among subjects with very low occupational mercury exposure. J Occup Environ Med 1998; 40: 1090-1101.

31. CETESB (São Paulo State Sanitary Agency). Notícias. Relatório de qualidade do ar no estado de São Paulo. CETESB http://www.cetesb.sp.gov.br; 2003.

32. Poulsen OM, Holst E, Christensen JM. Calculation and application of coverage intervals for biological reference values. Pure Appl Chem 1997; 69: 1601-1611.

33. CLSI (Clinical and Laboratory Standards Institute). Defining, establishing and verifying reference intervals in the clinical laboratory: approved guidelines. 3rd edn. Wayne: Vol. 28, No. 30, Document C28-A3; 2008.

34. Buratti M, Colombi A, Maroni M, Ferioli A, Foá V. Measurement of urinary porphyrin excretion in a reference population and in individuals exposed to workplace contaminants. In: Ho MH, Dillon HK (Editors), Biological monitoring of exposure to chemicals: organic compounds. New York: Wiley; 1987. p 309-319.

35. Schreiber WE, Raisys VA, Labbe RF. Liquid-chromatographic profiles of urinary porphyrins. Clin Chem 1983; 29: 527-530.

36. Klaassen CD, Ed. Casarett and Doull's toxicology: the basic science of poisons. 5th edn. New York: McGraw-Hill, 2001.

37. Santos JL, Grandal M, Fontanellas A, Moran MJ, Enriquez de SR. [Prevalence of porphyria cutanea tarda in Madrid and relationship between urine porphyrin and ethanol intake in a multiple linear regression model]. Med Clin 1996; 107: 614-616. 